\title{
Elevation correction of ERA-Interim temperature data in complex terrain
}

\author{
L. Gao, M. Bernhardt, and K. Schulz \\ Department of Geography, Ludwig-Maximilians-Universität München, Munich, Germany
}

Correspondence to: M. Bernhardt (m. bernhardt@iggf.geo.uni-muenchen.de)

Received: 27 March 2012 - Published in Hydrol. Earth Syst. Sci. Discuss.: 9 May 2012

Revised: 5 November 2012 - Accepted: 12 November 2012 - Published: 17 December 2012

\begin{abstract}
Air temperature controls a large variety of environmental processes, and is an essential input parameter for land surface models, for example in hydrology, ecology and climatology. However, meteorological networks, which can provide the necessary information, are commonly sparse in complex terrains, especially in high mountainous regions. In order to provide temperature data in an adequate temporal and spatial resolution for local scale applications a new elevation correction method has been developed that is able to downscale 3-hourly ERA-Interim temperature data. The scheme is based on model internal vertical lapse rates derived from different ERA-Interim pressure levels and has been validated for twelve meteorological stations in the German and Swiss Alps. The method was also compared with two other statistical, lapse rate based correction approaches. The results indicate that the use of model internal ERA-Interim lapse rates can significantly improve the downscaling performance when compared to the standard procedure of using fixed lapse rates.
\end{abstract}

\section{Introduction}

The near surface air temperature $\left(T_{\mathrm{a}}\right)$ is an important control for a large variety of environmental processes and influences the local as well as the global water, energy and matter cycle (Prince et al., 1998; Prihodko and Goward, 1997; Bolstad et al., 1998). Changes in $T_{\mathrm{a}}$ have a distinct influence on biogeochemical processes, the turbulent exchange between surface and atmosphere as well as on plant growth and many other components at the interface between the Earth's surface and atmosphere (Nieto et al., 2011; Regniere, 1996; Bolstad et al., 1998; Stahl et al., 2006). Therefore, historic, current and future temperature time series are needed for analyzing possible changes and impacts on the environment (Barry, 1992; Pepin and Seidel, 2005). They can also provide reliable data for decision-makers (e.g. tourism planning) and model developers (Dodson and Marks, 1997; Minder et al., 2010; Maurer et al., 2002; Mooney et al., 2011).

The most common sources for $T_{\mathrm{a}}$ time series are meteorological stations. However, meteorological networks are sparse in complex terrains, in particular at high altitudes, such as in mountains. This is mainly due to difficulties with the installation and maintenance of the stations (Kunkel, 1989; Rolland, 2003). Hence, information about $T_{\mathrm{a}}$ has to be calculated on the basis of surrounding stations, which are usually far away from the point of interest. The $T_{\mathrm{a}}$ can also be calculated with the help of climate models, which usually have a limited spatial resolution (Dodson and Marks, 1997; Vicente-Serrano et al., 2003; Ishida and Kawashima, 1993). Both methods tend to work well in homogeneous terrains, but tend to fail in heterogeneous terrains, where changes in the surface temperature can occur over short distances. Reasons for failure are the misrepresentations of key relationships between $T_{\mathrm{a}}$ and elevation (DeGaetano and Belcher, 2007) and the limitations of climate models to consider small-scale variations of the land surface.

Hence, lapse rates $(\Gamma)$, which display the empirical relationship between $T_{\mathrm{a}}$ and altitude, are often used to interpolate measurements or to scale model results of $T_{\mathrm{a}}$ with respect to elevation as well as for generating the required small-scale information of $T_{\mathrm{a}}$ (e.g. Wörlen et al., 1999). In this context, one has to distinguish between near surface temperature gradients (which are dominant if stations are interpolated) and free air lapse rates (which are used when different ERAInterim layers are used) in general. While the first one is 
dominated by the surface energy balance, surface roughness and near surface boundary layer effects, the second is mainly controlled by adiabatic effects and the current stratification of the atmosphere (Cullen and Marshall, 2011; Marshall et al., 2007). We use both kinds of lapse rates in this study and investigate their performance with respect to a correction of ERA-Interim model results.

The most common methods typically assume lapse rates in the range of $-6.0^{\circ} \mathrm{C} \mathrm{km}^{-1}$ (e.g. Dodson and Marks, 1997) to $-6.5^{\circ} \mathrm{C} \mathrm{km}^{-1}$ (e.g. Maurer et al., 2002; Lundquist and Cayan, 2007; Stahl et al., 2006), considering some similarity to the theoretical pseudo adiabatic lapse rate (Hamlet and Lettenmaier, 2005) or to the monthly variability of the temperature gradient within the atmosphere (Kunkel, 1989; Liston and Elder, 2006). However, many studies have proven that a fixed lapse rate may be problematic since the values of the lapse rate can vary significantly within short time periods of less than a month (Minder et al., 2010; Lundquist and Cayan, 2007; Rolland, 2003). The reason for these variations can be traced back to topographical characteristics of an area (Mahrt, 2006; Cullen and Marshall, 2011), the synoptic circulation (Pages and Miro, 2010; Blandford et al., 2008), the activity of the vegetation (Laughlin, 1982), seasonal variations with respect to the incoming radiation (Rolland, 2003; Blandford et al., 2008) and diurnal variations, e.g. due to a changing cloud cover (Minder et al., 2010). This lapse rate variability can only be monitored by dense meteorological station networks or by using alternative strategies that are able to cover the temporal and spatial variability of air temperature.

One such strategy, it to use global or regional scale climate model temperature outputs (e.g. reanalysis data) for different pressure levels that can also be used for a characterization of lapse rates and a subsequent downscaling of modeled temperatures without a direct use of observations (Maraun et al., 2010). Mokhov and Akperov (2006) used NCEP/NCAR reanalysis temperature profiles to investigate the relationship of tropospheric lapse rates and global averages of monthly surface temperatures. However, they focused on large scale patterns rather than testing this approach against local site data. In a similar way, Gruber (2012) applied the lowest seven pressure levels of NCEP data for the calculation of corrected surface temperatures. However, a detailed analysis of the quality of the method was not a focus.

We here present and test a newly developed elevation correction approach that is based on the European Centre for Medium Range Weather Forecast (ECMWF) reanalysis product ERA-Interim (Dee et al., 2011; Berrisford et al., 2011) with a focus on often critical Alpine environments. The method accounts for the temporal variability of lapse rates by using model internal temperature profiles. It allows for a scaling of $0.25^{\circ}$, 3-hourly ERA-Interim data to the point scale, and was tested and validated against two different standard correction methods (one based on station measurements, and another one that uses fixed data from literature) at twelve meteorological stations located in mountainous environments in the German and the Swiss Alps.

\section{Data and methods}

\subsection{ERA-Interim data}

We made use of the European Centre for Medium Range Weather Forecast (ECMWF) reanalysis product ERAInterim, which provides data from 1979 onwards, and continues in real time (Berrisford et al., 2009; Dee et al., 2011). The ERA-Interim project was launched in order to improve key aspects of ERA-40, such as the representation of the hydrological cycle, the quality of the stratospheric circulation, as well as the handling of biases and changes in the observing system (Dee and Uppala, 2009; Simmons et al., 2006; Uppala et al., 2008; Dee et al., 2011). This has been achieved by including many model improvements, as the use of 4-dimensional variation analysis, a revised humidity analysis, the use of variation bias correction for satellite data, and other improvements in data handling (Berrisford et al., 2009; Dee et al., 2011). Cycle 31r2 of ECMWF's Integrated Forecast System (IFS) was used for the ERAInterim product. The model in this configuration comprises 60 vertical levels, with the top level at $0.1 \mathrm{hPa}$; it uses the T255 spectral harmonic representation for the basic dynamical fields and a reduced Gaussian grid (N128) with an approximately uniform spacing of $79 \mathrm{~km}$ (Dee et al., 2011; Uppala et al., 2008). The atmospheric component is coupled to an ocean-wave model resolving 30 wave frequencies and 24 wave directions at the nodes of its reduced $1^{\circ} \times 1^{\circ}$ latitude/longitude grid. ERA-Interim assimilates four analyses per day at 00:00, 06:00, 12:00 and 18:00 UTC. Furthermore, two 10-day forecasts with a 3 -h resolution are initialized on the basis of the 00:00 UTC and 12:00 UTC analyses. Observations from 15:00 UTC of the previous day to 03:00 UTC on the present day are used for the 00:00 UTC analyses, and observations from 03:00 UTC to 15:00 UTC are used for 12:00 UTC analyses (Dee et al., 2011; Uppala et al., 2008).

ECMWF provides a variety of data in uniform latitude/longitude grids $\left(0.25^{\circ}, 0.5^{\circ}, 0.75^{\circ}, 1^{\circ}, 1.125^{\circ}, 1.5^{\circ}, 2^{\circ}\right.$, $2.5^{\circ}$ and $3^{\circ}$ ). The parameters (except vegetation, soil type fields and wave 2-D spectra) are interpolated from the original N128 reduced Gaussian grid using bilinear methods. The elevation dependency of the $2 \mathrm{~m}$ temperature is not considered within the interpolation scheme. Here, we applied 3-hourly forecast data (03:00, 06:00, 09:00, 12:00, 15:00, 18:00, 21:00 and 24:00 UTC) initialized at 00:00 UTC from 1979-2010 which were projected on a grid of $0.25^{\circ} \times 0.25^{\circ}$. The 00:00 UTC data were chosen, as the differences between 00:00 UTC and 12:00 UTC data are minor and not relevant for the achieved results. The used output variables are $2 \mathrm{~m}$ temperature, surface geopotential as well as temperature and geopotential height at $925 \mathrm{hPa}, 850 \mathrm{hPa}$ and $700 \mathrm{hPa}$ levels. 


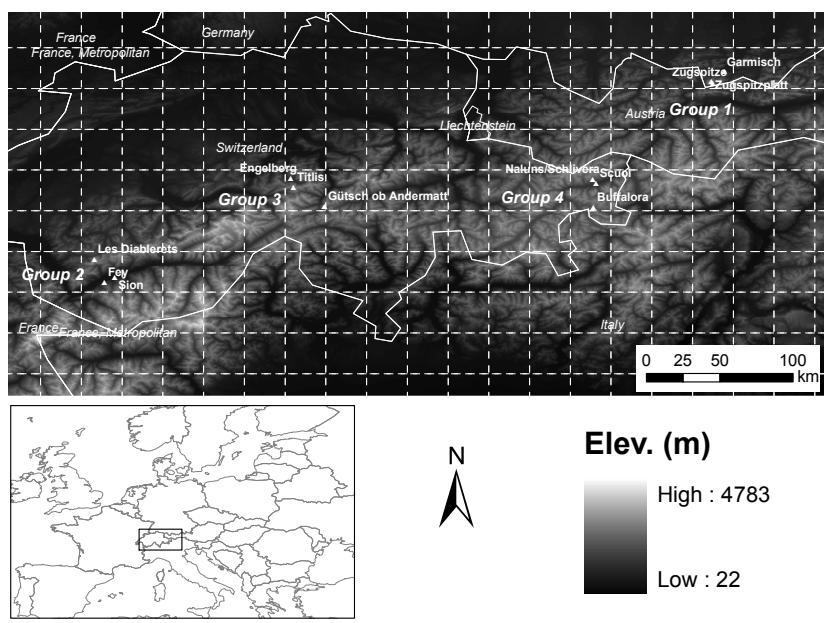

Fig. 1. Location of the twelve meteorological stations (triangles), and ERA-Interim $0.25^{\circ} \times 0.25^{\circ}$ grids (dashed line). Twelve stations were clustered into four groups according to the different ERAInterim grids. The elevation ranges from $22 \mathrm{~m}$ to $4783 \mathrm{~m}$ a.s.1., with a DEM resolution of $90 \mathrm{~m}$.

The geopotential height was calculated by the normalization of the geopotential over the gravity.

\subsection{Test sites}

The data from twelve test sites, all located in the German and Swiss Alps, have been used in the analysis. The stations are located within four different ERA-Interim grid elements and can be treated as four clusters of three stations (one at the valley bottom, one at the crest region and a station in between). A detailed description of the measurements and of the location of the different stations is given in Fig. 1 and Table 1. All measurements were aggregated to 3-hourly $\left(T_{3 \mathrm{~h}}\right)$ and daily $\left(T_{\mathrm{d}}\right)$ data for a later comparison with ERA-Interim data (Table 1). Days with missing values were excluded and were not used for any further analysis.

One important but difficult to answer question is whether individual stations might be used by ERA-Interim for assimilation purposes. If assimilated, the ERA-interim predictions are not fully independent from the observed data which were subsequently used for calibration and validation of the suggested downscaling methods. However, even a direct contact with the ECMWF personnel could not give a clear answer to this question (Pappenberger, personal communication, 2012). It is probable that the data of the stations Zugspitze, Garmisch and Sion are used for assimilation, given their status as WMO SYNOP stations (Simmons et al., 2010; Dee et al., 2011). According to the information of the ECMWF it can be assumed that at least the majority of the stations at Zugspitzplatt, Fey, Les Diablerets, Engelberg, Gütsch ob Andermatt, Titlis, Scuol, Buffalora and Naluns/Schlivera are not used by ERA-Interim and therefore represent fully independent data set.

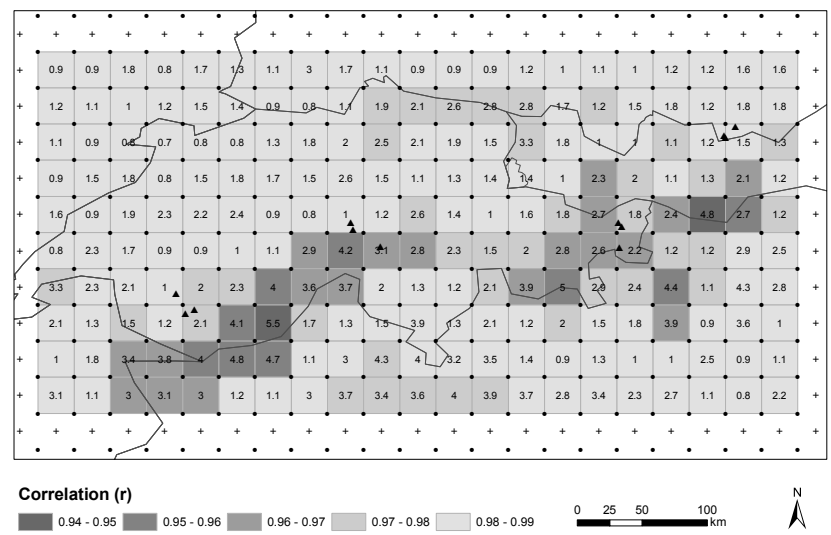

Fig. 2. Correlation and MAE $\left({ }^{\circ} \mathrm{C}\right)$ between daily mean ERAInterim $2 \mathrm{~m}$ temperature and E- 2 OBS data $\left(0.25^{\circ} \times 0.25^{\circ}\right.$, period from 1979 to 2010$)$ extended Simmons' investigation $\left(5^{\circ} \times 5^{\circ}\right.$, monthly, period from 1989 to 2001). The values labeled in the grid are the MAEs. The dots are the center points of ERA-Interim grid, the crosses are the center points of E-OBS grid and the triangles are the test sites. ERA-Interim and E-OBS grids are shifted in latitude and longitude direction by $0.125^{\circ}$, i.e. the center point of the E-OBS grid is located at the cross junction of four ERA-Interim grids. The average value of every four ERA-Interim points was calculated for the corresponding E-OBS grid.

\subsection{E-OBS database}

We used E-OBS data of the EU-FP6 ENSEMBLES project for validating the large scale error of the ERA-Interim results. The European daily high-resolution gridded data set of near-surface temperature (minimum, mean and maximum temperature) and precipitation (E-OBS) was operated as part of the EU-FP6 ENSEMBLES project (Haylock et al., 2008). Daily data were produced using a three-step interpolation on the basis of around 2300 stations while taking the elevation dependency of temperature into account (Haylock et al., 2008). The E-OBS dataset was produced for representing the best estimates of grid box averages. Gridded $0.25^{\circ}$ and $0.5^{\circ}$ latitude/longitude data were available as well as a $0.22^{\circ}$ and $0.44^{\circ}$ rotated pole grid with the North Pole at $39.25^{\circ} \mathrm{N}, 162^{\circ} \mathrm{W}$. The available data covers a large area $\left(25^{\circ}-75^{\circ} \mathrm{N}, 40^{\circ} \mathrm{W}-75^{\circ} \mathrm{E}\right)$ and a long time period. Here, we used the daily mean temperature with a $0.25^{\circ} \times 0.25^{\circ}$ spatial resolution from E-OBS version 6.0, which was released in April 2012 and which covers the period from 1950-2011. The time period of 1979-2010 was extracted for a comparison with the $0.25^{\circ} \times 0.25^{\circ}$ ERA-Interim $2 \mathrm{~m}$ temperature data. ERA-Interim and E-OBS data are shifted in latitude and longitude direction by $0.125^{\circ}$. The center point of the EOBS grid is located at the cross junction of four ERA-Interim grid elements (Fig. 2). Therefore, the average value of the four surrounding ERA-Interim points was calculated for the corresponding E-OBS value. 
Table 1. Test sites information (ERA_height is the ERA-Interim model elevation).

\begin{tabular}{|c|c|c|c|c|c|c|}
\hline & Site & latitude & $\begin{array}{r}\text { Altitude } \\
\text { longitude }\end{array}$ & $\begin{array}{r}\text { ERA_height } \\
\text { (m a.s.1) }\end{array}$ & (m a.s.l) & Time Series \\
\hline \multirow{3}{*}{ Group 1} & Garmisch & 47.48 & 11.07 & 719 & \multirow{3}{*}{1287} & 1979-2010 \\
\hline & Zugspitzplatt & 47.41 & 11.00 & 2250 & & 1999-2010 \\
\hline & Zugspitze & 47.42 & 10.99 & 2964 & & 1979-2010 \\
\hline \multirow{3}{*}{ Group 2} & Sion & 46.22 & 7.33 & 482 & \multirow{3}{*}{1408} & \multirow{3}{*}{ 2002-2004 } \\
\hline & Fey & 46.19 & 7.27 & 737 & & \\
\hline & Les Diablerets & 46.33 & 7.20 & 2966 & & \\
\hline \multirow{3}{*}{ Group 3} & Engelberg & 46.82 & 8.41 & 1036 & \multirow{3}{*}{1432} & \multirow{3}{*}{ 1994-2010 } \\
\hline & Gütsch ob Andermatt & 46.65 & 8.62 & 2287 & & \\
\hline & Titlis & 46.77 & 8.43 & 3040 & & \\
\hline \multirow{3}{*}{ Group 4} & Scuol & 46.79 & 10.28 & 1304 & \multirow{3}{*}{1818} & \multirow{3}{*}{ 1999-2010 } \\
\hline & Buffalora & 46.65 & 10.27 & 1968 & & \\
\hline & Naluns/Schlivera & 46.82 & 10.26 & 2400 & & \\
\hline
\end{tabular}

\subsection{Elevation correction methods}

Lapse rates $(\Gamma)$ describe the decrease of $T_{\mathrm{a}}$ with elevation. Equation (1) was used for all of the four presented correction methods, but the calculation of $T_{\text {ref }}$ and $\Gamma$ varied. $T_{\text {ref }}$ is the reference temperature, which was either defined by the ERA-Interim $2 \mathrm{~m}$ temperature ( $T_{\text {ERA_2m }}$ ) or the ERA-Interim temperature at the $850 \mathrm{hPa}$ pressure level ( $\left.T_{\text {ERA_850 }}\right)$.

$T_{t}=T_{\text {ref }}+\Gamma \times \Delta h$

We used four different methods for calculating $\Gamma$, Method (I) specific monthly lapse rates $\left(\Gamma_{\mathrm{S}}\right)$ extracted from literature, Method (II) measured lapse rates $\left(\Gamma_{M}\right)$, which were calculated on the basis of two meteorological stations covering the maximum elevation range of the area, and Method (III) and (IV) ERA-Interim lapse rates ( $\Gamma_{700 \_925}$ and $\left.\Gamma_{850 \_925} / \Gamma_{700 \_850}\right)$ which were calculated on the basis of temperatures at different pressure levels. Method I made use of monthly values of $\Gamma_{\mathrm{S}}$, which were calculated from the monthly mean maximum and minimum temperature data published by Kunkel (1989) and Liston and Elder (2006) (Table 2). These values have been widely applied in Earth surface modeling and their temporal resolution of one month can be seen as a standard with respect to generalized lapse rates (Bernhardt and Schulz, 2010; Mernild et al., 2009; Liston et al., 2008).

Method II used measured data from two meteorological stations for calculating 3-hourly and daily lapse rates. We used the highest and lowest elevated station per group for this calculation (Table 1). The lower elevated station represents the conditions at the valley bottom, while the higher elevated station is representative for the crest region. Method II was used as a benchmark for comparison with all other methods. Since stations at high elevation that are able to properly represent the meteorology are rare, other correction methods that are independent of surface measurements have to

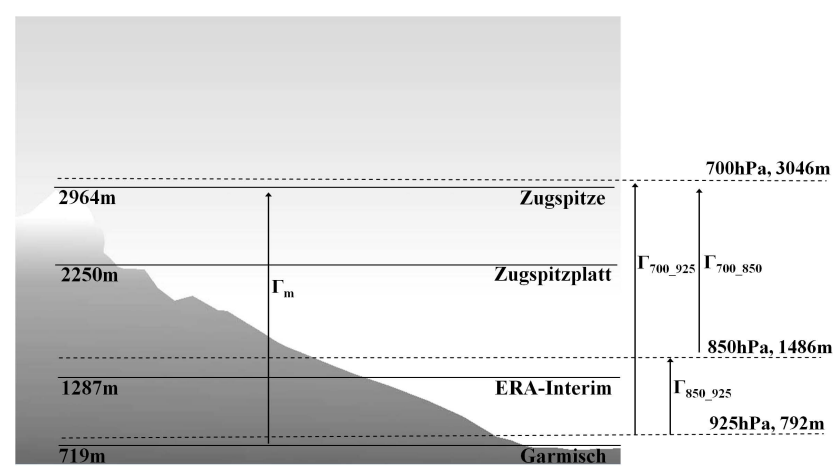

Fig. 3. Schematic illustration of measured lapse rate and ERAInterim derived lapse rates for Group $1 . \Gamma_{\mathrm{m}}$ was calculated based on the two largest-elevation-difference stations (e.g. Garmisch and Zugspizte station). Temperatures as well as the geopotential heights of the $700 \mathrm{hPa}, 850 \mathrm{hPa}$ and $925 \mathrm{hPa}$ level were used for calculating $\Gamma_{700 \_925}, \Gamma_{850 \_925}$ and $\Gamma_{700 \_850}$. The dashed blue line represents the mean geopotential height of the corresponding pressure level (for the period 1979-2010).

be developed (Blandford et al., 2008; Pages and Miro, 2010; Rolland, 2003).

In the following, we introduce two methods, which are based on ERA-Interim internal temperature gradients for addressing this need. Temperatures as well as the geopotential heights of the $700 \mathrm{hPa}, 850 \mathrm{hPa}$ and $925 \mathrm{hPa}$ level were used for calculating $\Gamma_{700 \_925}, \Gamma_{850 \_925}$ and $\Gamma_{700 \_850}$. This was done by calculating temperature differences between the $700 \mathrm{hPa}$ and $850 \mathrm{hPa}\left(\Gamma_{700 \_850}\right), 700 \mathrm{hPa}$ and $925 \mathrm{hPa}\left(\Gamma_{700 \_925}\right)$, as well as $850 \mathrm{hPa}$ and $925 \mathrm{hPa}\left(\Gamma_{850 \_925}\right)$ level (Fig. 3) and by dividing through the differences in the corresponding geopotential heights. 
Table 2. Fixed monthly lapse rates extracted from Kunkel (1989) and Liston and Elder (2006).

\begin{tabular}{rrrrrrrrrrrrr}
\hline & Jan & Feb & Mar & Apr & May & Jun & Jul & Aug & Sep & Oct & Nov & Dec \\
\hline Lapse rate $\left({ }^{\circ} \mathrm{C} \mathrm{km}^{-1}\right)$ & -4.4 & -5.9 & -7.1 & -7.8 & -8.1 & -8.2 & -8.1 & -8.1 & -7.7 & -6.8 & -5.5 & -4.7 \\
\hline
\end{tabular}

Table 3. Applied lapse rate $(\Gamma)$ and reference temperature $\left(T_{\text {ref }}\right)$ of four correction methods for twelve test stations.

\begin{tabular}{llll}
\hline Method & $\Gamma$ & $T_{\text {ref }}$ & Station \\
\hline Method I & $\Gamma_{\mathrm{S}}$ & $T_{\text {ERA_2m }}$ & All \\
Method II & $\Gamma_{\mathrm{m}}$ & $T_{\text {ERA_2m }}$ & All \\
& $\Gamma_{700 \_925}$ & $T_{\text {ERA_2m }}$ & $<1500 \mathrm{~m}$ a.s.l. \\
Method III & $\Gamma_{700 \_925}$ & $T_{\text {ERA_850 }}$ & $>1500 \mathrm{~m}$ a.s.l. \\
& $\Gamma_{850 \_925}$ & $T_{\text {ERA_2m }}$ & $<1500 \mathrm{~m}$ a.s.1. \\
Method IV & $\Gamma_{700 \_850}$ & $T_{\text {ERA_850 }}$ & $>1500 \mathrm{~m}$ a.s.l. \\
\hline
\end{tabular}

A differentiation into $\Gamma_{850 \_925}$ and $\Gamma_{700 \_850}$ was introduced to accommodate different atmospheric conditions and therefore dominant controls on surface temperature. While low altitudes are often influenced by local circulation patterns (represented by $\Gamma_{850 \_925}$ ), temperature conditions at higher elevations (represented by $\left.\Gamma_{700 \_850}\right)$ are more representative of free air flow conditions (Mahrt et al., 2001; Pepin and Seidel, 2005). Tabony (1985) noted that the transition from local circulation dominated to free air-dominated temperatures could be found at approximately $1400 \mathrm{~m}$ a.s.l. within the Austrian Alps. This estimate is used for splitting the temperature gradient into a lower, local flow dominated and a higher, free air flow dominated, gradient. For our test sites, the $850 \mathrm{hPa}$ level, varying around $1500 \mathrm{~m}$ a.s.l., was used as a transition level dividing the local circulation dominated zone, from the free air flow dominated zone. We used $T_{\text {ERA_850 instead of }}$ $T_{\text {ERA_2m }}$ as a basis for the calculation of the elevation correction for locations higher than $1500 \mathrm{~m}$. Figure 3 illustrates (for stations in group 1 as an example) the different parameters used in Eq. (1). Method III uses $T_{\text {ERA_2m }}$ and $\Gamma_{700 \_925}$ for the calculation of the temperature $\left(T_{\mathrm{a}}\right)$ at Garmisch station and $T_{\text {ERA_850 }}$ and $\Gamma_{700 \_925}$ for Zugspitze and Zugspitzplatt stations. In Method IV, $T_{\text {ERA_2m }}$ and $\Gamma_{850 \_925}$ are the basis for the calculation of $T_{\mathrm{a}}$ at Garmisch station and $T_{\text {ERA_850 }}$ as well as $\Gamma_{700 \_850}$ for Zugspitze and Zugspitzplatt stations (Table 3).

\section{Results}

\subsection{Validation of the uncorrected ERA-Interim temperature data}

In a first step, the quality of the uncorrected ERA-Interim data was analysed. We used a comparison of ERA and CRUTEM3 (gridded observations) data of Simmons et al. (2010), E-OBS data and station measurements for this comparison. Simmons et al. (2010) have shown that the large scale error of ERA-Interim $2 \mathrm{~m}$ temperature is generally small in Europe. They compared ERA-40 and ERAInterim monthly temperatures against CRUTEM3 results by using a $5^{\circ} \times 5^{\circ}$ grid. They found a high temporal correlation ( $r=0.997$ ) between CRUTEM3 and ERA-Interim results for the period from 1989 to 2001, with respect to Europe. It was shown that the accordance of ERA-Interim and CRUTEM3 is generally good with respect to large-scale patterns and magnitudes (Simmons et al., 2010). The investigations of Simmons et al. (2010) are extended here by using E-OBS data, given higher temporal (1 day) and spatial resolution $\left(0.25^{\circ}\right)$ and the availability of the data for the period from 1979-2010. A very good agreement between ERAInterim and E-OBS data with high correlation values (0.9470.992) was found (Fig. 2). Compared to Simmons' work, our comparison adopted a higher temporal resolution and a longer time period. The mean average error (MAE) between the two datasets became larger in the Alpine parts of the test area and could be connected to elevation differences between ERA-Interim model elevations and E-OBS grid elevations. By taking elevation differences into account and using Method I for data interpolation errors could be reduced and led to a reduction of the average MAE from 1.98 to $1.29^{\circ} \mathrm{C}$, and an increase of the correlation coefficient from 0.963 to 0.992. The simple elevation correction demonstrated that the existing errors can be well connected to elevation effects and that the large scale error of ERA-Interim is small in general.

A comparison of ERA-Interim results with the available meteorological stations underlined these results (Fig. 4). It can be seen that the $0.25^{\circ}$ ERA-Interim results show large deviations with respect to point measurements. This is especially true in case the elevation of the stations differ significantly from mean elevation of the corresponding ERAInterim grid elements. We found the largest biases for the higher elevated stations, while the stations located at the valley bottom show the highest accordance to the model (Table 4).

\subsection{Temporal variability of the lapse rates}

The different lapse rates $\left(\Gamma_{\mathrm{S}}, \quad \Gamma_{\mathrm{M}}, \quad \Gamma_{700} 925\right.$ and $\Gamma_{850 \_925} / \Gamma_{700 \_850}$, see Sect. 2.4$)$ show a different annual variability. Figure 5 illustrates the seasonal dynamics of measured and modeled lapse rates as well as those obtained from the literature. The latter ones do not show any inter-monthly variability as they are defined by a single 
Table 4. Comparison of ERA-Interim $2 \mathrm{~m}$ temperature with 3-hourly and daily data of twelve meteorological stations. The NSE as well as the RMSE and MAE in ${ }^{\circ} \mathrm{C}$ are also listed, and the elevations (m) are labeled in brackets.

\begin{tabular}{|c|c|c|c|c|c|c|c|c|c|}
\hline \multirow[t]{2}{*}{ Group 1} & \multicolumn{3}{|c|}{ Garmisch (719 m) } & \multicolumn{3}{|c|}{ Zugspitzplatt (2250 m) } & \multicolumn{3}{|c|}{ Zugspitze (2964 m) } \\
\hline & NSE & RMSE & MAE & NSE & RMSE & MAE & NSE & RMSE & MAE \\
\hline$T_{3 \mathrm{~h}}$ & 0.85 & 3.45 & 2.93 & 0.45 & 5.55 & 4.84 & -1.00 & 9.92 & 9.22 \\
\hline$T_{\mathrm{d}}$ & 0.85 & 3.03 & 2.76 & 0.51 & 4.95 & 4.47 & -0.93 & 9.52 & 9.09 \\
\hline \multirow[t]{2}{*}{ Group 2} & \multicolumn{3}{|c|}{ Sion (482 m) } & \multicolumn{3}{|c|}{ Fey (737 m) } & \multicolumn{3}{|c|}{ Les Diablerets (2966 m) } \\
\hline & NSE & RMSE & MAE & NSE & RMSE & MAE & NSE & RMSE & MAE \\
\hline$T_{3 \mathrm{~h}}$ & 0.50 & 6.20 & 5.76 & 0.48 & 5.77 & 5.32 & -0.79 & 8.61 & 7.78 \\
\hline$T_{\mathrm{d}}$ & 0.43 & 6.00 & 5.74 & 0.47 & 5.51 & 5.30 & -0.74 & 8.20 & 7.59 \\
\hline \multirow[t]{2}{*}{ Group 3} & \multicolumn{3}{|c|}{ Engelberg (1036 m) } & \multicolumn{3}{|c|}{ Gütsch ob Andermatt $(2287 \mathrm{~m})$} & \multicolumn{3}{|c|}{ Titlis $(3040 \mathrm{~m})$} \\
\hline & NSE & RMSE & MAE & NSE & RMSE & MAE & NSE & RMSE & MAE \\
\hline$T_{3 \mathrm{~h}}$ & 0.84 & 3.15 & 2.53 & 0.50 & 4.96 & 4.40 & -0.93 & 9.41 & 8.65 \\
\hline$T_{\mathrm{d}}$ & 0.87 & 2.69 & 2.22 & 0.57 & 4.49 & 4.14 & -0.88 & 9.00 & 8.51 \\
\hline \multirow[t]{2}{*}{ Group 4} & \multicolumn{3}{|c|}{ Scuol (1304 m) } & \multicolumn{3}{|c|}{ Buffalora (1968 m) } & \multicolumn{3}{|c|}{ Naluns/Schlivera $(2400 \mathrm{~m})$} \\
\hline & NSE & RMSE & MAE & NSE & RMSE & MAE & NSE & RMSE & MAE \\
\hline$T_{3 \mathrm{~h}}$ & 0.78 & 4.15 & 3.60 & 0.87 & 3.44 & 2.49 & 0.80 & 3.35 & 2.78 \\
\hline$T_{\mathrm{d}}$ & 0.78 & 3.77 & 3.49 & 0.91 & 2.52 & 1.83 & 0.86 & 2.73 & 2.39 \\
\hline
\end{tabular}

value per month. It can be seen that the lapse rates are generally smaller in winter but showed a higher variability during these colder months (October-February). Warmer months were characterized by lapse rates in the range of $-6^{\circ} \mathrm{C} \mathrm{km}^{-1}$ to $-7^{\circ} \mathrm{C} \mathrm{km}^{-1}$ and by a low inter-monthly variability (April-August). March and September represent transition months, where the regime changed from winter to summer or from summer to winter conditions. The between-group variability of the derived lapse rates also varied significantly. Group 2 shows the lowest variability, due to the very short time period of data availability. $\Gamma_{S}$ generally represents the largest temperature gradient and is significantly different from the measurements, especially during the summer months. $\Gamma_{700 \_925}$ and $\Gamma_{850 \_925} / \Gamma_{700 \_850}$ show larger variations during winter time and dynamics which are closer to the measurements $\left(\Gamma_{\mathrm{M}}\right)$. Only the temporal dynamics of Group 4 are not well covered by the ERA-Interim lapse rates. This group is located in the central Alps where the respective ERA-Interim grid elements do also show a large deviation from the E-OBS data. The overall difference between measured and modeled lapse rates is in general small in summertime (June-August) and shows stronger deviations in winter time (November-February), possibly due to frequent local inversion events during winter months that cannot be reproduced by the ERA-Interim model.

\subsection{Evaluation of correction methods}

In order to evaluate the presented correction methods, three statistical accuracy measures were used. The root mean square error (RMSE) and mean absolute error (MAE) are used for an assessment of the bias between corrected temperature and observation (Eqs. 2 and 3). The Nash-Sutcliffe efficiency coefficient (NSE) evaluates the performance of the correction methods using Eq. (4), which ranges from 1 (perfect fit) to minus infinity. A negative value of the NSE indicates that the model is a worse estimator than the mean of the observed data (Nash and Sutcliffe, 1970).

$$
\begin{aligned}
& \mathrm{RMSE}=\sqrt{\frac{1}{N} \sum_{t=1}^{N}\left(T_{\mathrm{o}}^{t}-T_{\mathrm{c}}^{t}\right)^{2}} \\
& \mathrm{MAE}=\frac{1}{N} \sum_{t=1}^{N}\left|T_{\mathrm{o}}^{t}-T_{\mathrm{c}}^{t}\right| \\
& \mathrm{NSE}=1-\frac{\sum_{t=1}^{N}\left(T_{\mathrm{o}}^{t}-T_{\mathrm{c}}^{t}\right)^{2}}{\sum_{t=1}^{N}\left(T_{\mathrm{o}}^{t}-\overline{T_{\mathrm{o}}}\right)^{2}}
\end{aligned}
$$

with $T_{\mathrm{o}}^{t}=$ observed temperature at time $t, T_{\mathrm{c}}^{t}=$ corrected temperature at time $t$, and $N=$ number of records.

The overall performance of the 4 correction methods is summarized in Table 5. Method III and IV outperformed Method II moderately regardless of whether $T_{3 \mathrm{~h}}$ or $T_{\mathrm{d}}$ data have been used. Method I generated the worst results. 

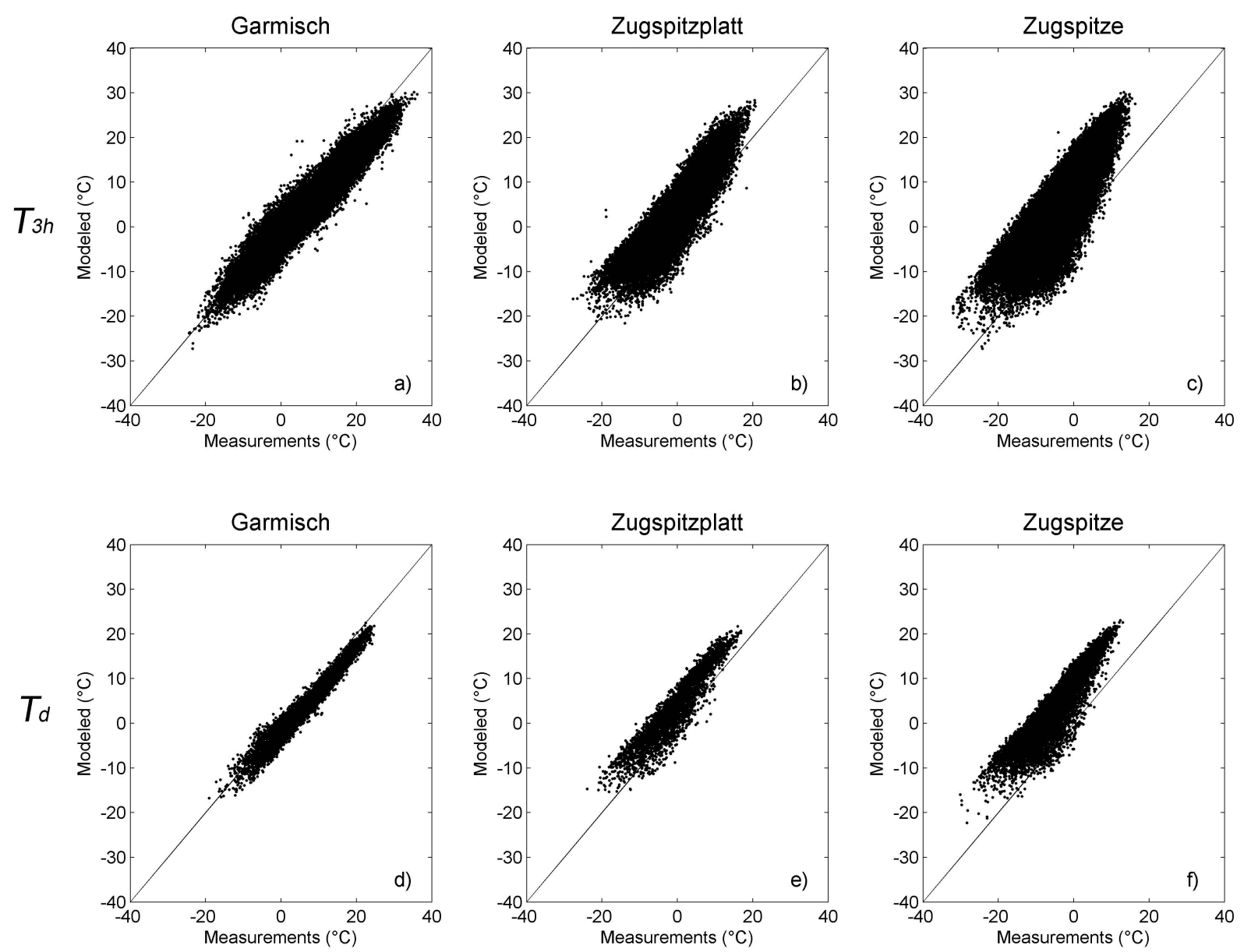

Fig. 4. The scatter plots show the comparison of 3-hourly ERA-Interim $2 \mathrm{~m}$ temperature and meteorological stations for Group 1, (a) Garmisch station (1979-2010), (b) Zugspitzplatt station (1999-2010) and (c) Zugspitze station (1979-2010). All the related accuracy measures can be found in Table 4 .

Table 5. Comparison of measurements with corrected 3-hourly and daily data for 4 methods by averaging NSE, RMSE and MAE statistics of all 12 test sites.

\begin{tabular}{lrrrrrr}
\hline & \multicolumn{3}{c}{$T_{\mathbf{3 h}}$} & & \multicolumn{2}{c}{$T_{\mathbf{d}}$} \\
\hline Method & \multirow{2}{*}{ NSE } & RMSE & MAE & NSE & RMSE & MAE \\
\hline I & 0.78 & 3.37 & 2.60 & 0.85 & 2.59 & 2.09 \\
II & 0.91 & 2.31 & 1.77 & 0.95 & 1.63 & 1.25 \\
III & 0.92 & 2.21 & 1.64 & 0.95 & 1.57 & 1.15 \\
IV & 0.92 & 2.21 & 1.65 & 0.95 & 1.56 & 1.14 \\
\hline
\end{tabular}

The specific performance of the four correction methods with respect to 3-hourly temperature data is summarized in Table 6. Figure 6 gives a more detailed visualization of the results given by Group 1. Method I worked well for stations located in the valley bottom, showed only moderate improvements for the average altitude stations, and even failed for the higher elevated stations (Table 6 and Fig. 6). Station Fey is an exception, showing the second best results (with respect to the NSE, RMSE and MAE) when Method I is applied (Table 6). Method II delivered the best results for the valley stations, but showed also acceptable results for the average altitude and high altitude stations. However, Method III and IV outperformed Method II for seven out of eight average and high altitude stations (Table 6). The reduction of the MAE for the valley stations was between $34.0 \%$ (Engelberg) and $73.6 \%$ (Sion), when using Method II. The MAE could also be improved for the average altitude stations (improvement between $53.8 \%$ and $59.7 \%$ ) with the exception of Buffalora, which were less accurate than the original ERA-Interim results $\left(2.49^{\circ} \mathrm{C}\right.$, method I; $2.67^{\circ} \mathrm{C}$, Method II). The MAE at the high altitude stations was reduced to between $1.2^{\circ} \mathrm{C}$ (Naluns/Schlivera) and $7.8^{\circ} \mathrm{C}$ (Zugspitze). Methods III and IV performed almost as well as our benchmark Method II, with particular good results for average and high altitude stations (Table 6). Another interesting result can be found at the high altitude station Titlis. Method II provided lapse rates without any outliers while the other methods show significant outliers for the period from to 4 December 1995 

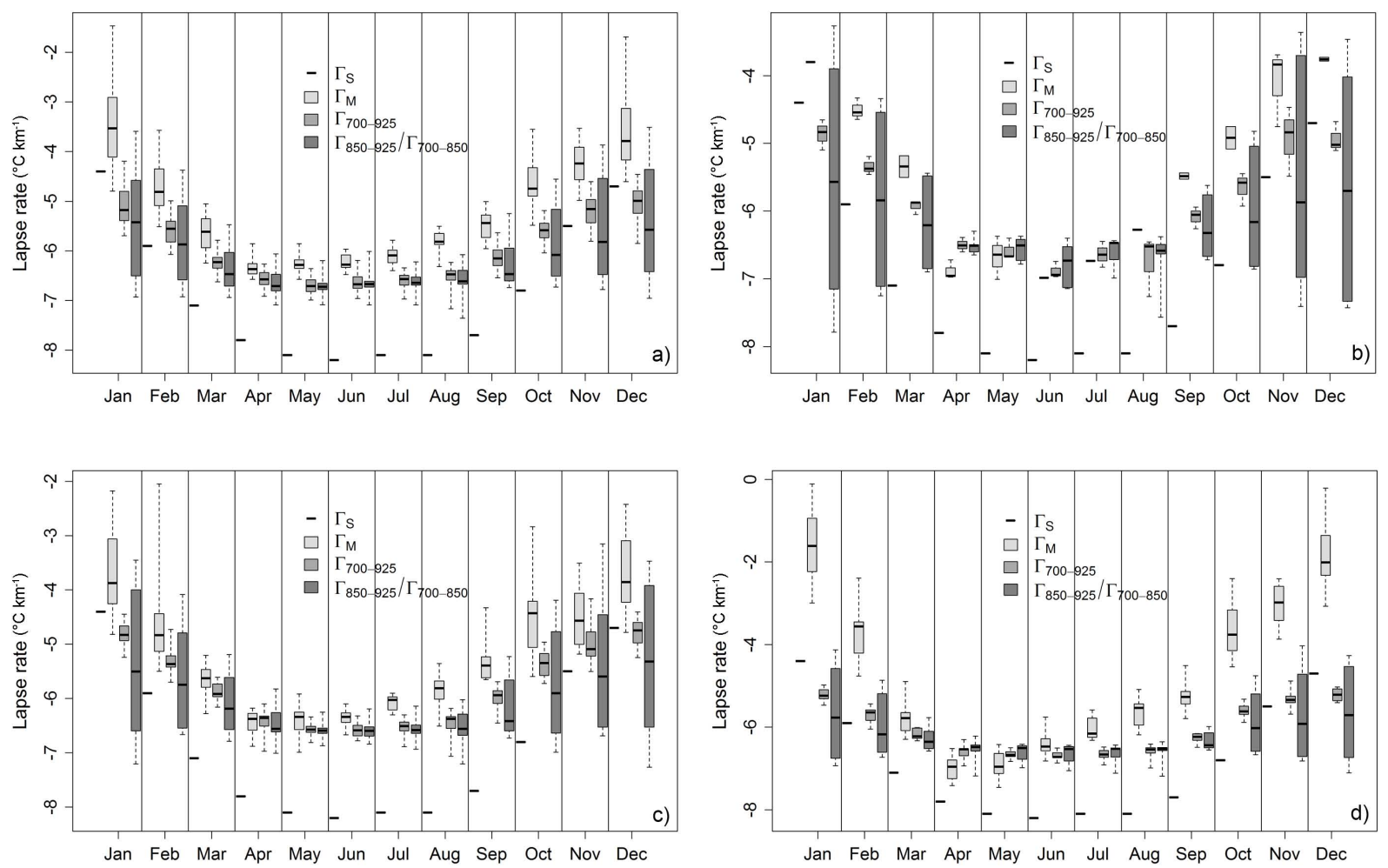

Fig. 5. Boxplots of monthly lapse rates for (a) Group 1 (1979-2010), (b) Group 2 (2002-2004), (c) Group 3 (1994-2010) and (d) Group 4 (1999-2010). $\Gamma_{\mathrm{S}}$ (short horizontal line), $\Gamma_{\mathrm{M}}$ (light gray), $\Gamma_{700 \_925}$ (medium gray) and $\Gamma_{850 \_925} / \Gamma_{700 \_850}$ (dark gray). Thick horizontal lines in boxes show the median values. Boxes indicate the inner-quantile range (25\% to $75 \%)$ and the whiskers show the full range of the values.

to 28 February 1996. The measurements show frequent and rapid changes with respect to the temperature. The temperatures reached high values, around $30^{\circ} \mathrm{C}$, and afterwards fall back to normal values (below of $0^{\circ} \mathrm{C}$ ) while the surroundings stations show no anomalies. Therefore, a measurement error at station Titlis has to be expected. Method II which is based on the measurements is consequently forcing the model results into the direction of the nonconforming measurements. The other methods which are independent of the station measurements do not reproduce this error. This is another example why methods which are independent of surface data are useful in high alpine areas where error-prone measurements are common. Furthermore, Methods III and IV performed very well at high altitude stations. The MAE at the average altitude stations could be reduced by $57.9 \%$ to $74.7 \%$ and by $59.4 \%$ to $87.9 \%$ for the high altitude stations. Nevertheless, the differences between Methods III and IV are negligible and an application of the simpler Method III seems to be sufficient, at least for the stations used in this study.

Figure 7 illustrates the performance of all 4 methods with respect to daily average temperatures, again by taking Group 1 as an example. While the accuracy of the correction results was similar when compared to the use of 3-hourly data, some additional interesting aspects can be analyzed for the aggregated data. For example, daily averages as well as daily minima and maxima temperature data are often used for characterizing local sites given current or predicted future climate conditions. Figure 7 clearly shows that the results at the lower end of the temperature spectrum were overestimated while warmer temperatures were underestimated. The extrapolation of the original ERA-Interim data or of data downscaled using Method I would therefore lead to a systematic misinterpretation of minimum and maximum values. This effect could only be eliminated when site specific lapse rates were used. This again is a strong argument against a general application of lapse rates, which are only oriented on stationary temperature gradient, but which do not factor in the local characteristics of a specific site.

\section{Discussion and conclusion}

In the previous sections correction methods for ERA-Interim temperature data on the basis of lapse rates have been described and analyzed. Certainly, the total error between a station measurement and an ERA-Interim prediction is not only due to the elevation difference between the ERA-Interim grid average and the individual site. Other factors, such as large scale biases of ERA-Interim, observation errors, model background errors, operator errors, errors resulting from the interpolation from original N128 reduced Gaussian grid to 

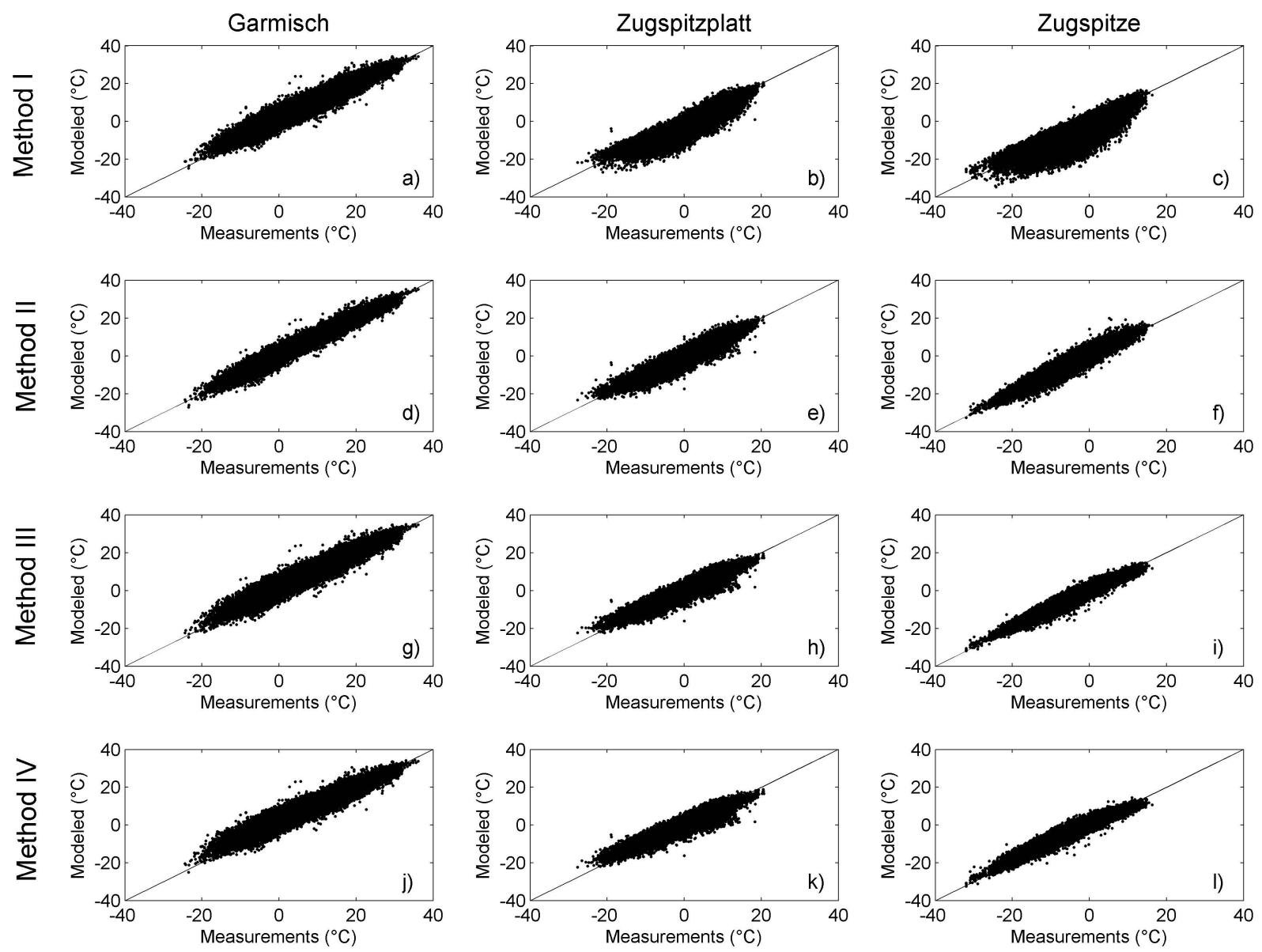

Fig. 6. The scatter plots show a comparison of measured and modeled 3-hourly temperatures for Group 1. (a, d, g, j) show the results of the different methods for Garmisch (1979-2010), (b, e, h, k) for Zugspitzplatt (1999-2010) and (c, f, I, l) for Zugspitze (1979-2010). All of the related accuracy measures can be found in Table 6.

latitude/longitude grids, and others, can affect the observed difference between the model and the measurements (Dee, 2005; Dee et al., 2011).

We were able to demonstrate that the large scale biases of ERA-Interim for temperature are very small, except for regions were the elevation differences between model grid and real world are high, as for example in the central Alps. Also, the total integral error between modeled and measured data was strongly reduced by using lapse rate approaches for elevation correction. In that context ERA-Interim internal lapse rate showed a better performance than observed lapse rate and reduced the RMSE and MAE for high altitudes. However, it has to be noted that even for some periods and locations significant differences between modeled and observed lapse rates could be observed.

The comparison between ERA-Interim $2 \mathrm{~m}$ temperature and E-OBS gridded data for the period from 1979 to 2010 indicates that elevation is the driving force for the observed error which therefore should be able to be corrected via elevation based approaches, such as lapse rates. Subsequently, $0.25^{\circ} \times 0.25^{\circ} 3$-hourly and daily ERA-Interim $2 \mathrm{~m}$ temperature data were compared with local measurements at twelve stations within the German and Swiss Alps. The comparison has illustrated that there is a need for a correction of ERAInterim data if it should be used at a given point in the mountains. The results in Table 4 make clear that a correction is neccessary for accounting for elevation driven temperature variations in heterogeneous mountain terrain, which cannot be represented by the original ERA-Interim grid.

Four different methods were used to derive the needed lapse rates $\Gamma$ : a fixed monthly lapse rate $\left(\Gamma_{S}\right)$ extracted from the literature (Method I); a measured lapse rate $\left(\Gamma_{\mathrm{M}}\right)$ (Method II); and ERA-Interim model internal lapse rates $\left(\Gamma_{700 \_925}\right.$ and $\left.\Gamma_{850 \_925} / \Gamma_{700 \_850}\right)$ derived from predictions at different pressure levels (Method III and IV).

Observed changes of lapse rates with elevation and with time demonstrated that the use of fixed lapse rates $\left(\Gamma_{\mathrm{S}}\right)$ were not satisfactory and led to large biases between corrected and locally measured temperature values, especially for high elevation stations. Method II represented an almost ideal 
Table 6. Comparison of measurements with corrected 3-hourly and daily data for group 1-4. The NSE as well as the RMSE and MAE in ${ }^{\circ} \mathrm{C}$ are also listed.

\begin{tabular}{|c|c|c|c|c|c|c|c|c|c|c|}
\hline \multicolumn{2}{|c|}{ Group 1} & \multicolumn{3}{|c|}{ Garmisch } & \multicolumn{3}{|c|}{ Zugspitzplatt } & \multicolumn{3}{|c|}{ Zugspitze } \\
\hline & Method & NSE & RMSE & MAE & NSE & RMSE & MAE & NSE & RMSE & MAE \\
\hline \multirow[t]{4}{*}{$T_{3 \mathrm{~h}}$} & I & 0.91 & 2.70 & 2.13 & 0.71 & 4.07 & 3.11 & 0.59 & 4.47 & 3.46 \\
\hline & II & 0.96 & 1.84 & 1.40 & 0.88 & 2.56 & 1.95 & 0.93 & 1.84 & 1.40 \\
\hline & III & 0.92 & 2.44 & 1.87 & 0.91 & 2.31 & 1.74 & 0.96 & 1.45 & 1.12 \\
\hline & IV & 0.91 & 2.62 & 1.99 & 0.91 & 2.29 & 1.73 & 0.94 & 1.73 & 1.33 \\
\hline \multirow[t]{4}{*}{$T_{\mathrm{d}}$} & I & 0.94 & 2.00 & 1.64 & 0.79 & 3.22 & 2.61 & 0.74 & 3.47 & 2.89 \\
\hline & II & 0.98 & 1.07 & 0.82 & 0.94 & 1.76 & 1.37 & 0.98 & 1.07 & 0.82 \\
\hline & III & 0.95 & 1.69 & 1.29 & 0.96 & 1.36 & 1.07 & 0.98 & 1.00 & 0.78 \\
\hline & IV & 0.94 & 1.91 & 1.43 & 0.97 & 1.31 & 1.03 & 0.96 & 1.32 & 1.00 \\
\hline \multicolumn{2}{|c|}{ Group 2} & \multicolumn{3}{|c|}{ Sion } & \multicolumn{3}{|c|}{ Fey } & \multicolumn{3}{|c|}{ Les Diablerets } \\
\hline & Method & NSE & RMSE & MAE & NSE & RMSE & MAE & NSE & RMSE & MAE \\
\hline \multirow{4}{*}{$T_{3 \mathrm{~h}}$} & I & 0.92 & 2.47 & 1.98 & 0.90 & 2.60 & 2.00 & 0.46 & 4.74 & 3.68 \\
\hline & II & 0.94 & 2.03 & 1.52 & 0.83 & 3.21 & 2.46 & 0.90 & 2.03 & 1.52 \\
\hline & III & 0.92 & 2.45 & 1.89 & 0.87 & 2.88 & 2.24 & 0.89 & 2.13 & 1.31 \\
\hline & IV & 0.93 & 2.32 & 1.81 & 0.90 & 2.55 & 1.99 & 0.90 & 2.04 & 1.25 \\
\hline \multirow[t]{4}{*}{$T_{\mathrm{d}}$} & I & 0.94 & 1.92 & 1.54 & 0.93 & 1.94 & 1.47 & 0.60 & 3.91 & 3.26 \\
\hline & II & 0.96 & 1.56 & 1.15 & 0.89 & 2.46 & 1.90 & 0.94 & 1.56 & 1.15 \\
\hline & III & 0.94 & 1.90 & 1.46 & 0.92 & 2.18 & 1.64 & 0.92 & 1.79 & 1.02 \\
\hline & IV & 0.95 & 1.74 & 1.35 & 0.94 & 1.83 & 1.40 & 0.93 & 1.62 & 0.86 \\
\hline \multicolumn{2}{|c|}{ Group 3} & \multicolumn{3}{|c|}{ Engelberg } & \multicolumn{3}{|c|}{ Gütsch ob Andermatt } & \multicolumn{3}{|c|}{ Titlis } \\
\hline & Method & NSE & RMSE & MAE & NSE & RMSE & MAE & NSE & RMSE & MAE \\
\hline \multirow[t]{4}{*}{$T_{3 h}$} & I & 0.89 & 2.60 & 2.01 & 0.78 & 3.33 & 2.52 & 0.56 & 4.50 & 3.44 \\
\hline & II & 0.92 & 2.19 & 1.67 & 0.89 & 2.35 & 1.78 & 0.89 & 2.19 & 1.67 \\
\hline & III & 0.90 & 2.51 & 1.89 & 0.95 & 1.54 & 1.18 & 0.92 & 1.92 & 1.18 \\
\hline & IV & 0.90 & 2.48 & 1.86 & 0.95 & 1.50 & 1.16 & 0.92 & 1.94 & 1.24 \\
\hline \multirow{4}{*}{$T_{\mathrm{d}}$} & I & 0.93 & 2.02 & 1.61 & 0.86 & 2.57 & 2.05 & 0.70 & 3.57 & 2.89 \\
\hline & II & 0.96 & 1.53 & 1.18 & 0.95 & 1.59 & 1.19 & 0.95 & 1.53 & 1.18 \\
\hline & III & 0.94 & 1.82 & 1.38 & 0.98 & 1.01 & 0.77 & 0.95 & 1.48 & 0.88 \\
\hline & IV & 0.94 & 1.85 & 1.41 & 0.98 & 0.96 & 0.74 & 0.95 & 1.51 & 0.97 \\
\hline \multicolumn{2}{|c|}{ Group 4} & \multicolumn{3}{|c|}{ Scuol } & \multicolumn{3}{|c|}{ Buffalora } & \multicolumn{3}{|c|}{ Naluns/Schlivera } \\
\hline & Method & NSE & RMSE & MAE & NSE & RMSE & MAE & NSE & RMSE & MAE \\
\hline \multirow[t]{4}{*}{$T_{3 \mathrm{~h}}$} & I & 0.94 & 2.26 & 1.80 & 0.89 & 3.21 & 2.46 & 0.79 & 3.45 & 2.66 \\
\hline & II & 0.95 & 2.00 & 1.57 & 0.86 & 3.51 & 2.67 & 0.93 & 2.00 & 1.57 \\
\hline & III & 0.94 & 2.23 & 1.75 & 0.89 & 3.22 & 2.46 & 0.96 & 1.47 & 1.10 \\
\hline & IV & 0.93 & 2.38 & 1.87 & 0.89 & 3.16 & 2.42 & 0.96 & 1.51 & 1.13 \\
\hline \multirow[t]{4}{*}{$T_{\mathrm{d}}$} & I & 0.97 & 1.43 & 1.14 & 0.93 & 2.21 & 1.59 & 0.85 & 2.85 & 2.34 \\
\hline & II & 0.97 & 1.51 & 1.23 & 0.92 & 2.43 & 1.72 & 0.96 & 1.51 & 1.23 \\
\hline & III & 0.97 & 1.49 & 1.18 & 0.93 & 2.18 & 1.57 & 0.98 & 0.99 & 0.78 \\
\hline & IV & 0.96 & 1.58 & 1.23 & 0.94 & 2.14 & 1.55 & 0.98 & 0.95 & 0.75 \\
\hline
\end{tabular}

situation where the complete vertical elevation/temperature gradient is covered by two stations providing continuously measured lapse rates. While this approach provided the best results, it would be interesting to analyze how far these measured lapse rates could be extrapolated in a spatial context.
A major disadvantage of Method II is its dependency on the availability of meteorological stations; only very few places in mountainous and high altitude regions worldwide can offer such a station setup. Furthermore, the usage of measured lapse rates can lead to the fact that the model is forced into 

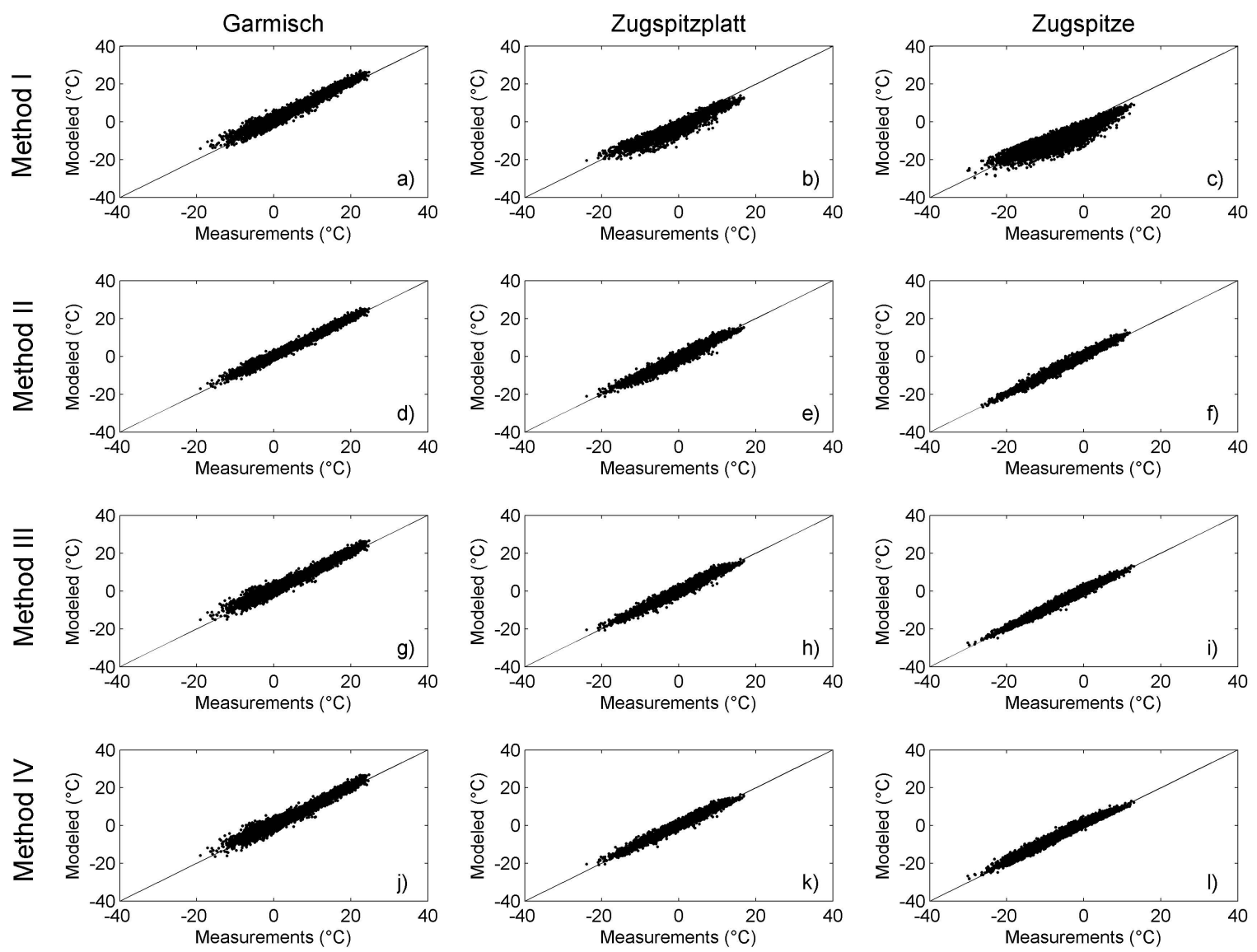

Fig. 7. The scatter plots show a comparison of measured and modeled daily temperature averages for Group 1. (a, d, g, j) show the results of the different methods for Garmisch (1979-2010), (b, e, h, k) for Zugspitzplatt (1999-2010) and (c, f, I, l) for Zugspitze (1979-2010). All of the related accuracy measures can be found in Table 6 .

the direction of implausible temperatures if one of the stations which are used for calculating the lapse rate delivers incorrect measurements.

Method III and IV represent alternatives for deriving temperature lapse rates by using (global climate) model (here ERA-Interim) internal lapse rates from representative pressure levels. Both methods showed a convincing performance when compared to measured data of the twelve stations, again especially for those in higher elevations. The ERAInterim internal lapse rate is a useful tool for correcting the original output data to the station scale, even if they underestimate the observed lapse rates for most of the entire season. The additional implementation of an internal baseline at approximately $1500 \mathrm{~m}$ and the calculation of separate lapse rates above and below (Method IV), allowed a vertical differentiation and the consideration of local circulation effects (below) and the dominance of free air conditions (above) on the temperature distribution (Mahrt, 2006; Rolland, 2003; Blandford et al., 2008). However, results only showed minimal differences between Method III and IV for the used test sites.
So far, our analysis has been limited to German and Swiss Alps with 12 meteorological stations providing calibration/validation data sets for testing developed correction methods. It will be necessary to extend this analysis to different high mountainous areas around the world. It should also be investigated whether other global reanalysis products, using different land surface representations in their climate models can be used in context with the presented approach. Also, the potential of extending our approach to other meteorological variables has to be explored and is a topic of on-going and future research.

Acknowledgements. ERA-Interim data was supported by the ECMWF. We want to thank Florian Pappenberger, scientist at ECMWF, and Carsten Maaß, expert at the User Support Center of ECMWF, for their valuable contributions regarding ERAInterim data preparation and processing. The authors appreciate the support of the Lawinenwarndienst Bayern (LWD) and MeteoSwiss, for providing meteorological data. We acknowledge the E-OBS dataset from the EU-FP6 project ENSEMBLES (http://ensembles-eu.metoffice.com) and the data providers in the ECA\&D project (http://eca.knmi.nl). We want to thank the 
two anonymous reviewers for their valuable comments and also appreciate the editor's suggestion.

Edited by: J. Seibert

\section{References}

Barry, R. G.: Mountain Climatology and Past and Potential Future Climatic Changes in Mountain Regions - a Review, Mt Res. Dev., 12, 71-86, 1992.

Bernhardt, M. and Schulz, K.: SnowSlide: A simple routine for calculating gravitational snow transport, Geophys. Res. Lett., 37 , L11502, doi:10.1029/2010g1043086, 2010.

Berrisford, P., Dee, D., Fielding, K., Fuentes, M., Kallberg, P., Kobayashi, S., and Uppala, S.: The ERA-Interim archive (version 1.0), ERA Report Series: European Centre for Medium Range Weather Forecasts, 2009.

Berrisford, P., Kallberg, P., Kobayashi, S., Dee, D., Uppala, S., Simmons, A. J., Poli, P., and Sato, H.: Atmospheric conservation properties in ERA-Interim, Q. J. Roy. Meteorol. Soc., 137, 13811399, doi:10.1002/Qj.864, 2011.

Blandford, T. R., Humes, K. S., Harshburger, B. J., Moore, B. C., Walden, V. P., and Ye, H. C.: Seasonal and synoptic variations in near-surface air temperature lapse rates in a mountainous basin, J. Appl. Meteorol. Clim., 47, 249-261, doi:10.1175/2007jamc1565.1, 2008.

Bolstad, P. V., Swift, L., Collins, F., and Regniere, J.: Measured and predicted air temperatures at basin to regional scales in the southern Appalachian mountains, Agr. Forest Meteorol., 91, 161-176, 1998.

Cullen, R. M. and Marshall, S. J.: Mesoscale Temperature Patterns in the Rocky Mountains and Foothills Region of Southern Alberta, Atmos. Ocean, 49, 189-205, doi:10.1080/07055900.2011.592130, 2011.

Dee, D. and Uppala, S.: Variational bias correction in ERA-Interim, ECMWF Newsletter, No. 119, 21-29, 2009.

Dee, D. P.: Bias and data assimilation, Q. J. Roy. Meteorol. Soc., 131, 3323-3343, doi:10.1256/Qj.05.137, 2005.

Dee, D. P., Uppala, S. M., Simmons, A. J., Berrisford, P., Poli, P., Kobayashi, S., Andrae, U., Balmaseda, M. A., Balsamo, G., Bauer, P., Bechtold, P., Beljaars, A. C. M., van de Berg, L., Bidlot, J., Bormann, N., Delsol, C., Dragani, R., Fuentes, M., Geer, A. J., Haimberger, L., Healy, S. B., Hersbach, H., Holm, E. V., Isaksen, L., Kallberg, P., Kohler, M., Matricardi, M., McNally, A. P., Monge-Sanz, B. M., Morcrette, J. J., Park, B. K., Peubey, C., de Rosnay, P., Tavolato, C., Thepaut, J. N., and Vitart, F.: The ERA-Interim reanalysis: configuration and performance of the data assimilation system, Q. J. Roy. Meteorol. Soc., 137, 553597, doi:10.1002/Qj.828, 2011.

DeGaetano, A. T. and Belcher, B. N.: Spatial interpolation of daily maximum and minimum air temperature based on meteorological model analyses and independent observations, J. Appl. Meteorol. Clim., 46, 1981-1992, doi:10.1175/2007JAMC1536.1, 2007.

Dodson, R. and Marks, D.: Daily air temperature interpolated at high spatial resolution over a large mountainous region, Clim. Res., 8, 1-20, 1997.

Gruber, S.: Derivation and analysis of a high-resolution estimate of global permafrost zonation, The Cryosphere, 6, 221-233, doi:10.5194/tc-6-221-2012, 2012.

Hamlet, A. F. and Lettenmaier, D. P.: Production of temporally consistent gridded precipitation and temperature fields for the continental United States, J. Hydrometeorol., 6, 330-336, 2005.

Haylock, M. R., Hofstra, N., Tank, A. M. G. K., Klok, E. J., Jones, P. D., and New, M.: A European daily highresolution gridded data set of surface temperature and precipitation for 1950-2006, J. Geophys. Res.-Atmos., 113, D20119, doi:10.1029/2008jd010201, 2008.

Ishida, T. and Kawashima, S.: Use of Cokriging to Estimate Surface Air-Temperature from Elevation, Theor. Appl. Climatol., 47, 147-157, 1993.

Kunkel, E. K.: Simple Procedures for Extrapolation of Humidity Variables in the Mountainous Western United States, J. Climate, 2, 656-669, 1989.

Laughlin, G. P.: Minimum Temperature and Lapse-Rate in Complex Terrain - Influencing Factors and Prediction, Arch. Meteor. Geophy. B, 30, 141-152, 1982.

Liston, G. E. and Elder, K.: A meteorological distribution system for high-resolution terrestrial modeling (MicroMet), J. Hydrometeorol., 7, 217-234, 2006.

Liston, G. E., Hiemstra, C. A., Elder, K., and Cline, D. W.: Mesocell Study Area Snow Distributions for the Cold Land Processes Experiment (CLPX), J. Hydrometeorol., 9, 957-976, doi:10.1175/2008jhm869.1, 2008.

Lundquist, J. D. and Cayan, D. R.: Surface temperature patterns in complex terrain: Daily variations and long-term change in the central Sierra Nevada, California, J. Geophys. Res.-Atmos., 112, D11124, doi:10.1029/2006jd007561, 2007.

Mahrt, L., Vickers, D., Nakamura, R., Soler, M. R., Sun, J. L., Burns, S., and Lenschow, D. H.: Shallow drainage flows, Bound.Lay. Meteorol., 101, 243-260, 2001.

Mahrt, L.: Variation of surface air temperature in complex terrain, J. Appl. Meteorol. Clim., 45, 1481-1493, 2006.

Maraun, D., Wetterhall, F., Ireson, A. M., Chandler, R. E., Kendon, E. J., Widmann, M., Brienen, S., Rust, H. W., Sauter, T., Themessl, M., Venema, V. K. C., Chun, K. P., Goodess, C. M., Jones, R. G., Onof, C., Vrac, M., and Thiele-Eich, I.: Precipitation Downscaling under Climate Change: Recent Developments to Bridge the Gap between Dynamical Models and the End User, Rev. Geophys., 48, Rg3003, doi:10.1029/2009rg000314, 2010.

Marshall, S. J., Sharp, M. J., Burgess, D. O., and Anslow, F. S.: Near-surface-temperature lapse rates on the Prince of Wales Icefield, Ellesmere Island, Canada: implications for regional downscaling of temperature, Int. J. Climatol., 27, 385-398, doi:10.1002/Joc.1396, 2007.

Maurer, E. P., Wood, A. W., Adam, J. C., Lettenmaier, D. P., and Nijssen, B.: A long-term hydrologically based dataset of land surface fluxes and states for the conterminous United States, J. Climate, 15, 3237-3251, 2002.

Mernild, S. H., Liston, G. E., Hiemstra, C. A., Steffen, K., Hanna, E., and Christensen, J. H.: Greenland Ice Sheet surface mass-balance modelling and freshwater flux for 2007, and in a 1995-2007 perspective, Hydrol. Process., 23, 2470-2484, doi:10.1002/Hyp.7354, 2009.

Minder, J. R., Mote, P. W., and Lundquist, J. D.: Surface temperature lapse rates over complex terrain: Lessons from the Cascade Mountains, J. Geophys. Res.-Atmos., 115, D14122, doi:10.1029/2009jd013493, 2010. 
Mokhov, I. I. and Akperov, M. G.: Tropospheric lapse rate and its relation to surface temperature from reanalysis data, Izv Atmos. Ocean Phy.+, 42, 430-438, doi:10.1134/S0001433806040037, 2006.

Mooney, P. A., Mulligan, F. J., and Fealy, R.: Comparison of ERA-40, ERA-Interim and NCEP/NCAR reanalysis data with observed surface air temperatures over Ireland, Int. J. Climatol., 31, 545-557, doi:10.1002/Joc.2098, 2011.

Nash, J. E. and Sutcliffe, J. V.: River flow forecasting through conceptual models part I - A discussion of principles, J. Hydrol., 10, 282-290, 1970.

Nieto, H., Sandholt, I., Aguado, I., Chuvieco, E., and Stisen, S.: Air temperature estimation with MSG-SEVIRI data: Calibration and validation of the TVX algorithm for the Iberian Peninsula, Remote Sens. Environ., 115, 107-116, doi:10.1016/j.rse.2010.08.010, 2011.

Pages, M. and Miro, J. R.: Determining temperature lapse rates over mountain slopes using vertically weighted regression: a case study from the Pyrenees, Meteorol. Appl., 17, 53-63, doi:10.1002/Met.160, 2010.

Pepin, N. C. and Seidel, D. J.: A global comparison of surface and free-air temperatures at high elevations, J. Geophys. Res.Atmos., 110, D03104, doi:10.1029/2004JD005047, 2005.

Prihodko, L. and Goward, S. N.: Estimation of air temperature from remotely sensed surface observations, Remote Sens. Environ., 60, 335-346, 1997.

Prince, S. D., Goetz, S. J., Dubayah, R. O., Czajkowski, K. P., and Thawley, M.: Inference of surface and air temperature, atmospheric precipitable water and vapor pressure deficit using Advanced Very High-Resolution Radiometer satellite observations: comparison with field observations, J. Hydrol., 213, 230-249, 1998.
Regniere, J.: Generalized approach to landscape-wide seasonal forecasting with temperature-driven simulation models, Environ. Entomol., 25, 869-881, 1996.

Rolland, C.: Spatial and seasonal variations of air temperature lapse rates in Alpine regions, J. Climate, 16, 1032-1046, 2003.

Simmons, A., Uppala, S., Dee, D., and Kobayashi, S.: ERA-Interim: New ECMWF reanalysis products from 1989 onwards, ECMWF Newsletter, No. 110, 25-35, 2006.

Simmons, A. J., Willett, K. M., Jones, P. D., Thorne, P. W., and Dee, D. P.: Low-frequency variations in surface atmospheric humidity, temperature, and precipitation: Inferences from reanalyses and monthly gridded observational data sets, J. Geophys. Res.-Atmos., 115, D01110, doi:10.1029/2009jd012442, 2010.

Stahl, K., Moore, R. D., Floyer, J. A., Asplin, M. G., and McKendry, I. G.: Comparison of approaches for spatial interpolation of daily air temperature in a large region with complex topography and highly variable station density, Agr. Forest Meteorol., 139, 224236, 2006.

Tabony, R. C.: The Variation of Surface-Temperature with Altitude, Meteorol. Mag., 114, 37-48, 1985.

Uppala, S., Dee, D., Kobayashi, S., Berrisford, P., and Simmons, A.: Towards a climate data assimilation system: status updata of ERA-Interim, ECMWF Newsletter, No. 115, 12-18, 2008.

Vicente-Serrano, S. M., Saz-Sanchez, M. A., and Cuadrat, J. M.: Comparative analysis of interpolation methods in the middle Ebro Valley (Spain): application to annual precipitation and temperature, Climate Res., 24, 161-180, 2003.

Wörlen, C., Schulz, K., Huwe, B., and Eiden, R.: Spatial extrapolation of agrarmeteorological variables, Agric. For. Meteorol., 94, 233-242, 1999. 